\title{
Does Unemployment Still Follow Hysteresis Hypothesis in Nigeria? Evidence from Linear and Nonlinear Unit Root Test Methods
}

\author{
Isiaka Akande Raifu (MSc) \\ Department of Economics, \\ Faculty of Economics and Management Sciences \\ University of Ibadan, Ibadan, Oyo State, Nigeria

\section{Temitope Titus Abodunde (MSc)} \\ Department of Economics, \\ Faculty of Economics and Management Sciences, \\ University of Ibadan, Ibadan, Oyo State, Nigeria
}

\begin{abstract}
In the face of persistent rise in unemployment figure in Nigeria, this study re-examines the unemployment hysteresis hypothesis by deploying both linear and nonlinear unit root estimation techniques. Using Nigerian unemployment rate data from 1970 to 2017, evidence from the adopted unit toot test techniques, except the quantile unit root test, showed that unemployment hysteresis hypothesis holds in Nigeria. This implies that when a shock that affects unemployment occurs, there is a high tendency that the effect would be permanent. However, the finding from the quantile unit root test sheds light on the need for a timely policy response. If the policy interventions such as fiscal policy and other forms of policies are taken regularly, especially at every quarter, the tendency for unemployment to revert to its pre-shock state is high.
\end{abstract}

Keywords: Unemployment, Unemployment Hysteresis Hypothesis, Unit Root Tests

\section{Introduction}

One of the fundamental macroeconomic problems facing Nigeria is the problem of unemployment. Figure 1 shows the trend of unemployment over time. The figure reveals that the unemployment rate has been rising over the years. Historically, the problem of unemployment began in the late 1970s after the discovery of crude oil at Oloibiri and its commercialisation. The problem is further fuelled by the abandoning of the agricultural sector. It can be recalled that the agricultural sector was the main driver of the economy before the discovery of crude oil. Due to the boom experienced in the oil sector and the seeming unattractiveness of the agricultural sector, many workers in agricultural sector abandoned farming and other agricultural-related businesses in search of job opportunities in the urban areas where oil sector was perceived to be booming. However, due to the inability of the oil sector to absorb the influx of the 


\section{Journal of International Cooperation and Development \\ www.richtmann.org/journal \\ Vol 3, No 1, May 2020}

workers, many of them became unemployed when they got to the urban areas (Ofuoku and Chukwuji, 2012; Nuga and Asimiea, 2015). Apart from this, several other factors have been ascribed to have contributed to the incessant rise in unemployment in Nigeria. These factors include a persistent rise in young population, dysfunctional education system, mismanagement of public resources, corruption at different levels of government, lack of infrastructural facilities, lack of capacity utilisation, obsolescence or deterioration of skills due to a long state of unemployment, inconsistent in government policies, economic uncertainty and poor enabling environment among others (Raifu, 2017; Aminu and Raifu, 2018, Raifu, 2019).

Due to psychological, socio-economic and political consequences of high persistent unemployment, researchers have conducted several empirical studies on the issue related to the unemployment problem. One of these issues that have gained prominence in labour economics is the unemployment hysteresis. Blanchard and Summer (1986) pioneered this area of research. They employed two theories to explain the rationale for high persistent unemployment in Europe. These theories include membership theories and duration theories. The membership theories depend on the ideas of insider-and-outsider workers dichotomy and wage-setting bargaining power. Duration theories, on the other hand, rests on the fact that there is a tendency for an unemployed person to remain unemployed for a very long-time. Specifically, Blanchard and Summer (1986) opine that unemployment depends on its historical path. Consequently, when shock occurs that affects unemployment, unemployment tends not to return to its long-run equilibrium. Practically, it implies that unemployment is characterised by unit root process (Blanchard and Summer 1987, Barro, 1988). Aside from the Hysteresis hypothesis, other hypotheses have been used to explain high persistent unemployment. These hypotheses (theories) are Natural Rate of Unemployment (Phelps, 1967, 1972; Friedman, 1968), Structural Theory of Unemployment (Phelps, 1994) and Persistence Hypothesis Unemployment (Nelson and Plosser, 1982).

Since the proposition of these hypotheses, several empirical studies have been conducted to test the validity of any of the hypothesis. With regard to testing the validity of unemployment hysteresis hypothesis (hereafter UHH), Blanchard and Summer $(1986,1987)$ used the data of countries such as the US, France, the UK and Germany to test whether UHH is valid or not in those countries. They, however, found that out of the four countries, only in the US is the UHH is rejected. In other countries, UHH exists. Several other studies have been conducted in many countries to affirm the veracity of $\mathrm{UHH}$, however, the findings from these sundries of studies appear to be mixed (see literature review section for details). While UHH has been tested in many countries (developed, developing and emerging countries), such study seems to be limited in Nigeria. The few available studies on Nigeria include Folawewo (2012); Ayinde, Egbetunde and Bankole, (2014); Ayinde and Egbetunde (2015) and Onwukeme and 


\section{Journal of International Cooperation and Development \\ www.richtmann.org/journal \\ Vol 3, No 1, May 2020}

Opeloyeru (2015). All these studies tested UHH using linear unit root test such as ADF, P$\mathrm{P}$ and Lumsdaine-Papell, Zivot-Andrews tests). In other words, none of these studies has used nonlinear unit root test methods to verify the veracity of UHH in Nigeria. Given this, the current study does not only reconsider the linear methods of investigating UHH but also extends the investigation to the use of a nonlinear methods. More specifically, we use three common linear unit root test methods-Augment Dickey-Fuller (ADF), Phillips and Perron (P-P) and Kwiatkowski-Phillips-Schmidt-Shin (KPSS) unit root tests to ascertain the veracity of previous studies and then use four nonlinear unit root test methods- Kapetanios, Shin and Snell unit root test (KSS, 2003), quantile unit root test by Koenker and Xiao (2004), Kruse (2011) and Fourier unit root test by Enders and Lee, (2004; 2012). Considering nonlinear relations in economic parlance has been the preoccupation of researchers over time. This is because it is believed that the best way to model macroeconomic series is to consider nonlinear method (Neftci, 1984). The nonlinear behaviour of the economic series rests on the argument that when the economic downturn occurs, economic series fall sharply than when the economic recovery occurs owing to the assumption of downward rigidity of wages and prices (Romer, 2012).

The rest of the study is organized as follows: Section 2 reviews extant studies. Section 3 presents methodological approaches, data sources and descriptive analysis of the data. Findings and discussion of the findings are presented in Section 4 while Section 5 concludes with policy implications.

\section{Literature Review}

Aside from the theoretical or hypotheses that provide the rationales for high persistent unemployment, several empirical studies have been conducted to investigate the validity of UHH across different countries. One common fact from these sundries of extant studies is that the findings are varied depending on the country or the groups of countries under consideration and the econometric techniques deployed by the researchers. It is important to note that both linear and nonlinear approaches have been used to test UHH. The main preoccupation here is to briefly summarise some of these findings along whether UHH holds or not.

We begin the review by first focusing on advanced economies of the US, European countries and OECD countries. The study conducted by Gustavsson and Österholm (2006), using the data of Australia, Austria, Canada, Finland, Sweden, the UK and the US, showed that unemployment hysteresis is only evident in Australia, Canada and the US. While Romero-Ávila and Usabiaga (2007) who investigated the validity of UHH in the 50 states of the US found that out of the 50 states, UHH only holds in 39 states, BahmaniOskooee, Chang and Ranjbar (2017) who retested UHH also in the 52 states of the US, however, found that UHH holds in all 52 states. The discrepancy in their findings could 


\section{Journal of International Cooperation and Development}

www.richtmann.org/journal

Vol 3, No 1, May 2020

be attributed to different econometric estimation techniques and the scope of their studies. For instance, Romero-Ávila and Usabiaga (2007) used monthly data that covered a period from 1976 to 2004 and adopted Lagrange multiplier unit root test as an estimation technique while Bahmani-Oskooee, Chang and Ranjbar (2017) also used monthly data spanning the period from 1976 to 2016 and deployed quantile unit root test method for estimation. Regional evidence on UHH from Turkey and the Czech Republic yield mixed results as well. In Turkey, evidence of UHH was found in all the 26 regions considered (Gözgör, 2013). In the Czech Republic, only in 5 regions out of 14 regions was the evidence of UHH not found (Furuoka, 2014b). Focusing on OECD countries, Chang (2011) examined UHH in 17 OECD countries and found that hysteresis occurred in most of the countries except in Australia, Canada, Finland, Sweeden and the US. Khraief, et al. (2015), however, noted that accounting for a structural break in the data could alter the results. By considering 29 OECD countries while accounting for a structural break, they found that UHH is rejected in all the 29 OECD countries (see also Lin, Kuo and Yuan, 2008). Kula and Aslan (2010) considered the testing of UHH along with the level of educational attainment. Their results showed that UHH only holds at a primary and secondary level of education. In most of the studies that focused on European countries, UHH holds (Dritsaki and Dritsaki, 2013-for Greece, Ireland and Portugal; Bolat, Tiwari and Erdayi 2014-for 17 European countries, Galí, 2015; Xie, et al., 2018-for Hungary and Romania and Caporale and Gil-Alana, 2018 for Spain).

In the countries of Asian and Africa, the empirical evidence reported is also diverse (Chang, et al., 2007; Lee, Wu and Lin, 2010; Eisazadeh and Tabarsi, 2013; Furuoka, 2014a; Caporale and Gil-Alana, 2018; Pikoko and Phiri, 2019; Yaya, Ogbonna and Mudida 2019). Chang et al. (2007) found no evidence of UHH in all the 21 regions of Taiwan. The results documented by Lee, Wu and Lin (2010) showed that there exists UHH in all the East-Asian countries considered including Taiwan. Caporale and Gil-Alana (2018) explored the validity of UHH in 11 African countries using a fractional integration approach. Their results revealed that unemployment in all 11 countries exhibits hysteresis. However, extending the number of countries to 42 and using Fourier ADF unit root method, Yaya et al. (2019) found that UHH only holds in 7 countries out the 47 countries. Pikoko and Phiri (2019) probed the validity of UHH considering 8 categories of unemployment in South Africa. They confirmed UHH for all categories of unemployment except persons aged between 55 and 65 years old.

We now turn to the few studies that focused on Nigeria (Folawewo, 2012; Ayinde, Egbetunde and Bankole, 2014; Ayinde and Egbetunde, 2015 and Onwukeme and Opeloyeru, 2015). Two observations could be deduced from these studies. First, all the studies used linear unit root test methods (whether they accounted for a structural break or not) to test UHH. Second, almost all of them documented the evidence that supports UHH except the study by Olanipekun, et al. (2017) who found that UHH does not hold in Nigeria. However, considering the linear approach to verify the validity of 


\section{Journal of International Cooperation and Development \\ www.richtmann.org/journal \\ Vol 3, No 1, May 2020}

UHH could yield biased findings because most of the macroeconomic series including unemployment follows an asymmetric pattern over time. In light of this, this study considers nonlinear approach in conjunction with linear approach to test the validity of $\mathrm{UHH}$.

\section{Methodological Approaches, Data Source and Description}

To re-examine UHH in Nigeria, we used three linear unit root tests and four nonlinear unit root tests. The linear unit root tests used are Augmented Dickey-Fuller (ADF), Phillips-Perron (PP) and Kwiatkowski-Phillips-Schmidt-Shin (KPSS) unit root tests while the nonlinear unit root tests are Kapetanios, Shin and Snell (KSS), Kruse. Fourier Augmented Dickey-Fuller and Quantile Augmented Dickey-Fuller unit root tests. The frameworks of these unit root tests are presented one after the other beginning from linear unit root tests and then followed by nonlinear unit root tests.

\subsubsection{Augmented Dickey-Fuller Unit Root Test}

Since it was developed in 1979 by David Dickey and Wayne Fuller, ADF has been used in several studies as a preliminary estimation technique to ascertain the stationarity property of macroeconomic series. In labour economics, particularly with regard to testing the validity of $\mathrm{UHH}$, the stationarity property of unemployment series offers a clue on whether a rise in unemployment figure would return to its original state after the shock to the economy or the shock would have a permanent effect on unemployment. The framework of ADF usually follows the AR(1) process specified as:

$$
u n_{t}=\beta+\gamma t+\rho u n_{t-1}+\varepsilon_{t}
$$

Where $u n_{t}$ is the unemployment rate, $\beta, \gamma$ and $\rho$ are the coefficient parameters, $t=1, \ldots, T$ and $\varepsilon_{t}$ is the error term assumed to be distributed with constant mean and equal variance. The unemployment rate has a unit root if $\rho=1$ equation 1 can be reparameterised as:

$$
\Delta u n_{t}=\beta+\gamma t+\delta u n_{t-1}+\sum_{i=1}^{p} \lambda_{i} \Delta u n_{t-i}+\varepsilon_{t}
$$

Where $\delta=\rho-1$ is the new null hypothesis and it implies that unemployment series follows a random walk, $\Delta$ is the difference operator. If $\delta=0$ unemployment series is not stationary. Hence, UHH holds.

\subsubsection{Phillips-Perron Unit Root Test}

Phillip-Perron unit root test is developed by Peter Phillips and Pierre Perron in 1988. Although their method is akin to the ADF framework, it, however, differs by accounting 


\section{Journal of International Cooperation and Development \\ www.richtmann.org/journal \\ Vol 3, No 1, May 2020}

for serial correlation and heteroscedasticity in the error term of the equation. The P-P test regression is usually fitted using OLS. The P-P is specified:

$$
u n_{t}=\varphi+\theta u n_{t-1}+\varepsilon_{t}
$$

\subsubsection{Kwiatkowski, Phillips, Schmidt and Shin Unit Root Test}

The KPSS unit root test was proposed by Denis Kwiatkowski, Peter Phillips, Peter Schmidt and Yongcheol Shin in 1992. The null hypothesis of KPSS is that series are stationary around the deterministic trend. They augmented ADF by accounting for the power and size of the finite selected sample. The underlying framework of KPSS is specified as:

$$
u n_{t}=\pi t+\lambda_{t}+\varepsilon_{t}
$$

Where $\lambda_{i}$ is a random walk that follows this $A R(1)$ process

$$
\lambda_{t}=\lambda_{t-1}+u_{t}
$$

Where ${ }^{u_{t}}$ is assumed to be independent and identically distributed with zero mean and constant variance $i i d\left(0, \sigma_{u}^{2}\right)$. $\lambda_{0}$ is often treated as fixed and it is referred to as an intercept. $\sigma_{u}^{2}$ is the stationarity assumption. Under this null hypothesis $u n_{t}$ is trendstationary because $\varepsilon_{i}$ is assumed to be stationary.

\subsubsection{Kapetanios, Shin and Snell (2003) Unit Root Test Framework}

Kapetanios, Shin and Snell, (2003) unit root test is a nonlinear version of a simple ADF unit root test. The nonlinear is introduced to detect the presence of nonstationarity against nonlinear stationary exponential smooth transition autoregressive process. The KSS unit root test is proposed because of the consistent failure of conventional Augmented Dickey-Fuller unit root test to reject the null hypothesis of a unit root in some macroeconomic or financial series. Following Yilanci (2008), the main KSS unit root test framework is presented as follows:

Consider an unemployment series having the following exponential smooth transition autoregressive process:

$$
\Delta u n_{t}=\beta u n_{t-1}\left\{1-\exp \left(-\alpha u n_{t-1}^{2}\right)\right\}+\varepsilon_{t}
$$

Where $\left\{1-\exp \left(-\alpha u n_{t-1}^{2}\right)\right\} \quad$ denotes the exponential transition function. To test the null hypothesis of no stationarity against the alternative, the focus is on the $\alpha$ parameter. It is assumed that $\alpha$ is zero under the null hypothesis and positive or greater than zero under the alternative hypothesis. The null hypothesis against the alternative hypothesis is formulated as:

The null hypothesis:

$$
H_{0}: \alpha=0
$$




\section{Journal of International Cooperation and Development \\ www.richtmann.org/journal \\ Vol 3, No 1, May 2020}

The alternative hypothesis:

$H_{0}: \alpha>0$

It is, however, to be noted that testing the null hypothesis from equation (8) is not feasible because $\beta$ is not directly observable from equation (6). To overcome this limitation, KSS re-parameterised equation (6) using first-order Taylor series approximation to arrive at equation (9) given as follows:

$$
\Delta u n_{t}=\gamma u n_{t-1}^{3}+v_{t}
$$

From equation (10) it is possible to obtain the $t$-test statistic for the null hypothesis $\gamma=0$ against the alternative hypothesis $\gamma<0$ as:

$$
t_{N L}=\hat{\gamma} / \text { s.e. }(\hat{\gamma})
$$

Where $\hat{\gamma}$ is the OLS estimate of $\gamma$ and s.e. $(\hat{\gamma})$ is the standard error of $\hat{\gamma}$.

\subsubsection{Kruse (2011) Unit Root Test Framework}

Owing to the restrictive assumption that characterised KSS, especially the assumption of the zero restriction on the parameter $\gamma$, Kruse (2011) proposes a new unit root that extends the KSS unit root test by relaxing the assumption of zero restriction. The Kruse unit root test is based on the assumption that $H_{0}: \phi_{1}=\phi_{2}=0$ against a globally stationary ESTAR process $H_{1}: \phi_{1}<0, \phi_{2} \neq 0$. The Kruse (2011) unit root test framework is presented as follows.

$$
\Delta y_{t}=\phi_{1} \Delta y_{t-1}^{3}+\phi_{2} \Delta y_{t-1}^{2}+\sum_{t=1}^{k} \rho_{i} \Delta y_{t-i}+u_{t}
$$

\subsubsection{Koenker and Xiao (2004) Quantile Unit Root Test Framework}

The linear unit root test methods such as ADF, PP, KPSS and others are applicable where explanatory power of the OLS assumptions of normality, homoscedasticity, no serial correlation and linearity are fulfilled. However, when any of these assumptions breakdown, the possibility of rejecting the null hypothesis of the unit root becomes implausible. To overcome this, Koenker and Xiao, (2004) proposed a new unit root test based on quantile autoregression approach. Generally, Quantile unit root test method is an extension of ADF that allows for the possibility of shocks of various sign and size to have different impacts on economic variables. Following Koenker and Xiao, (2004), Yushi and Tsangyao (2016) and Valera, Holmes and Hassan (2017), the quantile unit root test framework is presented as follows:

Beginning from a standard ADF unit root framework with deterministic trend $t$ given as:

$$
\Delta u n_{t}=\alpha_{t}+\beta t+\sum_{t-1}^{n} \gamma_{i} \Delta u n_{t-1}+\varepsilon_{t} ; t=n+1, n+2, \ldots, m
$$




\section{Journal of International Cooperation and Development \\ www.richtmann.org/journal \\ Vol 3, No 1, May 2020}

Where ${ }^{u n_{t}}$ denotes unemployment rate, $\alpha_{t}$ is an intercept term and $\varepsilon_{t}$ is an error term. In equation 12 , the measure of the persistence of unemployment denoted as $\mu$ is the sum of autoregressive coefficients $\sum_{t=1}^{n} \gamma_{i}$. Given the information above, equation 12 can be reparameterised as follows:

$u n_{t}=\alpha_{t}+\beta t+\mu u n_{t-1}+\sum_{i=1}^{n-1} \gamma_{i} \Delta u n_{t-1}+\varepsilon_{t}$

In the existing unit root test methods, particularly $A D F$, equation 13 can be estimated using OLS. If $\mu=0$, the unemployment process is not stationary, that is, contains unit root and thus the effect of any form of shock will be permanent on the unemployment rate. If, however, $\mu<1$, then the unemployment rate is stationary in trend and the effect of shocks on the unemployment rate is temporary. The range, $-2<$ $\mu<0$ provides the condition for stationarity properties of the unemployment rate (Valera, Holmes and Hassan 2017). The estimation of equation 13 using OLS provides a conditional mean estimate. However, to account for the heavy tails in the conditional distribution of the unemployment rate, the quantile autoregression method is applied. Following Koenker and Xiao, (2004), the conditional quantile distribution denoted as $\tau$ th for change in the unemployment rate is specified as:

$$
Q_{\Delta u n_{t}}\left(\tau \mid \Gamma_{t-1}\right)=\alpha_{t}(\tau)+\beta(\tau) t+\mu(\tau) u n_{t-1}+\sum_{i=1}^{n-1} \gamma_{i}(\tau) \Delta u n_{t-1}+\varepsilon_{t}
$$

$Q_{\Delta u n_{t}}\left(\tau \mid \Gamma_{t-1}\right)$ represents $\tau t h$ quantile of change in the unemployment rate which is conditional on the previous information set $\Gamma_{t-1} \cdot \mu(\tau)$ measures the speed of mean reversion of $\Delta u n_{t}$ within each quantile while $\alpha_{t}(\tau)$ measures the average size of unemployment shocks in each quantile. The equation 15 can be estimated by minimizing the sum of weighted absolute deviations asymmetrically as follows:

$$
\begin{aligned}
& \min _{t=1}^{n}\left(\tau-I\left(\text { un }<\alpha_{t}(\tau)+\beta(\tau) t+\mu(\tau) u n_{t-1}+\sum_{i=1}^{n-1} \gamma_{i}(\tau) \Delta u n_{t-1}\right)\right) \\
& \left|u n_{t}-\alpha_{t}(\tau)+\beta(\tau) t+\mu(\tau) u n_{t-1}+\sum_{i=1}^{n-1} \gamma_{i}(\tau) \Delta u n_{t-1}\right| \\
& \text { Where I=1 if } u n_{t}<\left(\alpha_{t}(\tau)+\beta(\tau) t+\mu(\tau) u n_{t-1}+\sum_{i=1}^{n-1} \gamma_{i}(\tau) \Delta u n_{t-1}\right) \\
& \text { and I=0 otherwise. }
\end{aligned}
$$

Given the equations (14) and (15), the $\mu(\tau)$ can be estimated at different quantile $(\tau \in(0.1)$. Thus, the null hypothesis of quantile unit root test given as $\mu(\tau)=1$ can then be tested at the different values of $\tau$ against the alternative hypothesis specified as: $\mu(\tau) \rightarrow \infty$. The Alkaike Information Criteria is used to select the optimal lag length. From the quantile regression carried out, the t-test for $\mu(\tau)$ can be estimated through the following formula proposed by Koenker and Xiao (2004):

$$
t_{n}(\tau)=\frac{f\left(F^{-1}(\tau)\right.}{\sqrt{\tau(1-\tau)}}\left(u n_{t-1}^{\prime} M_{Z} u n_{t-1}\right)^{1 / 2}(\mu(\tau)-1)
$$

Where $u n_{t-1}$ denotes the vector of lagged of the unemployment rate, $f\left(\widehat{F^{-1}}(\tau)\right.$ is the consistent estimator is $f\left(F^{-1}(\tau)\right.$, with $f(u)$ and $F(u)$ representing the probability and cumulative density function of the error term $\left(\varepsilon_{t}\right) . M_{Z}$ signifies the projection matrix onto the space orthogonal to $\mathrm{Z}=\left(1, \Delta u n_{t-1}, \Delta u n_{t-2}, \ldots, \Delta u n_{t-n}\right)$. The rule to estimate $f\left(F^{-1}(\tau)\right)$ as proposed by Koenker and Xiao, (2004) is given as: 


\section{Journal of International Cooperation and Development \\ www.richtmann.org/journal \\ Vol 3, No 1, May 2020}

$$
f\left(F^{-1}(\tau)\right)=\frac{\left(\tau_{i}-\tau_{i-1}\right)}{\left(x ^ { \prime } \left(\widehat{\mu}\left(\tau_{i}\right)-\left(\widehat{\mu}\left(\tau_{i-1}\right)\right)\right.\right.}
$$

Finally, for a complete inference as regards to the unit root process that is based on the quantile method, Koenker and Xiao, (2004) advocated the quantile KolmogorovSmirnov (QKS) test given as:

$Q K S=\sup _{\tau=\Gamma}\left|t_{n}(\tau)\right|$

Where $t_{n}(\tau)$ is computed using equation (16) and $\Gamma=(0.1 .0 .2,0.3, \ldots, 0.9)$, implying that can be computed across the quantile $\left(\tau_{s}\right)$ in $\Gamma$. Thereafter, the construction of the QKS test statistic in such a way that the maximum values are selected across $\Gamma$. However, QKS test statistics are non-standard, thus in this study, we follow the resampling procedures suggested by Koenker and Xiao, (2004). ${ }^{1}$ The procedures help to approximate small sample distributions.

\subsubsection{Fourier ADF Unit Root Test Framework}

The Fourier augmented Dickey-Fuller unit root test (FADF) is developed by Enders and Lee $(2004,2012)$. In the course of developing FADF, Enders and Lee approximate for a small number of smooth breaks in the deterministic components of data series. Following Enders and Lee $(2004,2012)$ as specified by Furuoka (2014a), the ADF framework is first specified as:

$$
\Delta u n_{t}=\varphi_{o}+\rho u n_{t-1}+\sum_{i=1}^{l} \varphi_{1} \Delta u n_{t-1}+\varepsilon_{t}
$$

Where $u n_{t}$ is the unemployment rate, $I$ is the lag length of the lagged values of represents a $\Delta u n_{t}, \varphi$ and $\rho$ are the parameters to be estimated, $\varepsilon_{t}$ denotes an error term. Given the null hypothesis of no unit root $(\rho=0)$, the FADF as suggested by Enderss and Lee (2012) is specified as:

$$
u n_{t}=\rho u n_{t}+\varphi+\vartheta_{1} \sin \left(\frac{2 \pi k t}{T}\right)+\vartheta_{2} \cos \left(\frac{2 \pi k t}{T}\right)+\sum_{i=1}^{l} \varphi_{1} \Delta u n_{t-1}+\varepsilon_{t}
$$

Where $k$ represents a given frequency selected for the Fourier approximation, $t$ denotes trend time, $T$ is the number of observation, $\vartheta$ 's connotes the parameters for the Fourier approximation and $\pi=3.1416$. The FADF statistic $\left(\left(\tau_{D F}\right)\right.$ represent the t-statistic with the null hypothesis $(\rho=0)$ in equation (20).

When the coefficients of trigonometric terms in Fourier's version of ADF $\left(\vartheta_{1}=\vartheta_{2}=0\right)$, then the FADF is simply a special case of ADF. To test whether the trigonometric terms be included in the model, Enders and Lee (2012) propose that the following F-statistic should be used.

$$
F(k)=\frac{\left(S S R_{0}-S S R_{1}\right) / q}{S S R_{k}(k) /(T-k)}
$$

Where $S S R_{o}$ is the SSR from $u n_{t}$ the regression without the trigonometric terms, $S S R_{1}$ is the sum of squared residual, $q$ denotes the number of restrictions and $k$ is the

\footnotetext{
${ }^{1}$ The details of the resampling procedures are provided by Koenker and Xiao, (2004)
} 


\section{Journal of International Cooperation and Development \\ www.richtmann.org/journal \\ Vol 3, No 1, May 2020}

number of regressors in the regression. As shown in equation (22), the FADF statistic depends on the frequency ( $k$ ) and the lag length (I). According to Enders and Lee (2012), a Fourier function with $\mathrm{k}=1$ or $\mathrm{k}=2$ serves as a realistic approximation that captures the structural breaks. The AIC used to select the optimal lag length (I) is computed as follows:

$$
A I C=-2\left(\frac{L}{T}\right)+2\left(\frac{k}{T}\right)
$$

Where $L$ is the log-likelihood and can be calculated as:

$$
L=-\frac{T}{2}\left(1+\ln (2 \pi)+\ln \left(\frac{\widehat{\varepsilon}^{\prime} \hat{\varepsilon}}{T}\right)\right)
$$

Where $\hat{\varepsilon}$ is the residual estimated from equation (20). For the lag length selection, it is important to specify the maximum lag length denoted as $I_{\max }$. Thus, Hayashi (2000) suggests the following equation to compute the maximum lag length:

$$
l_{\max }=\operatorname{int}\left(\frac{T}{3}\right)^{*}\left(\frac{T}{100}\right)^{1 / 4}
$$

Where int is the integer function which rounds off a real number to the nearest integer.

\subsection{Data Source and Description}

The unemployment data used for this study is extracted from the National Bureau of Statistics (NBS). The data is an annual data which covers a period from 1970 to 2017. According to the various issue released by NBS, unemployment is defined as the number of people who are willing to work and seriously searching for jobs but unable to find jobs. The Figure 1 below shows the trend of the unemployment rate over time in Nigeria. It can be observed that the unemployment rate has been rising over time, rising from less than $5 \%$ in the 1970 s to about over $35 \%$ in 2017 . Table 1 provides descriptive estimates of the unemployment rate. From the Table, the average unemployment rate stood at $9.91 \%$ which ranges from a minimum of $1.60 \%$ to a maximum of $37.38 \%$. The value of standard deviation stood at $9.27 \%$ implying the unemployment rate is not widely dispersed from its mean percentage. In other words, unemployment is less volatile in Nigeria.

Table 1: Descriptive Statistics Results

\begin{tabular}{cccccccccc}
\hline Variables & Obs & Mean & Std.Dev. & Min & Max & p1 & p99 & Skew. & Kurt. \\
\hline un & 48 & 9.912 & 9.27 & 1.6 & 37.38 & 1.6 & 37.38 & 1.277 & 3.618 \\
\hline
\end{tabular}

Note: un denotes unemployment rate 


\section{Journal of International Cooperation and Development \\ www.richtmann.org/journal \\ Vol 3, No 1, May 2020}

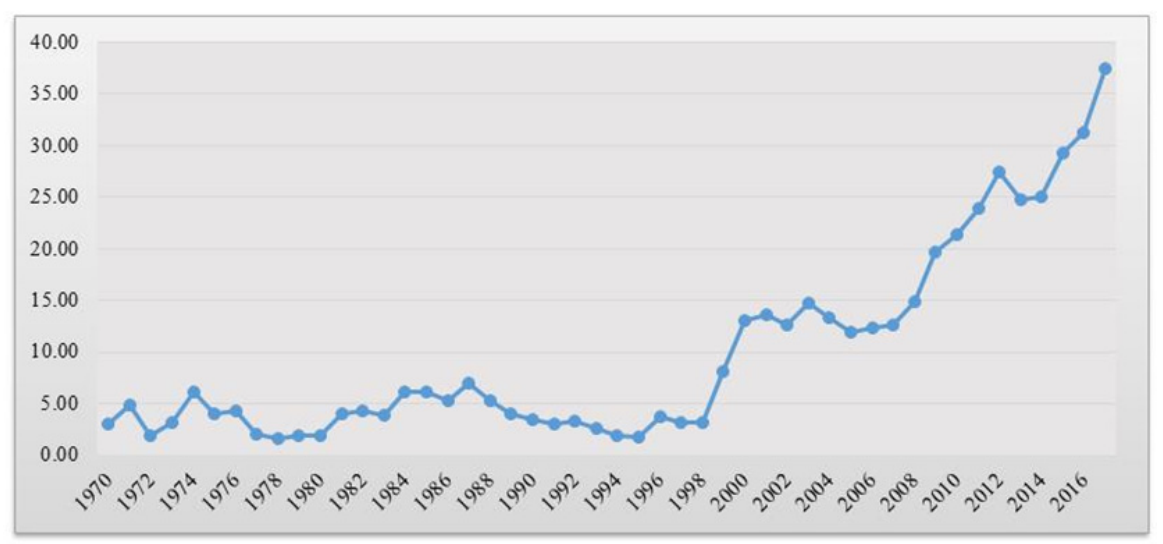

Figure 1: Trend of Unemployment Rate in Nigeria (1970-2017)

Source: Graphed by the authors from data obtained from the National Bureau of Statistics

\section{Empirical Results}

In this section, we present the results of linear and nonlinear unit root tests conducted to re-examine the existence of UHH in Nigeria. The results of linear unit root tests are presented in Table 2. According to the table, ADF, P-P and KPSS failed to reject the null hypothesis of a unit root in the unemployment rate in Nigeria. In other words, based on the linear unit root test, unemployment still follows a non-stationary process in Nigeria. This finding is indicative of a possibility that there is hysteresis in the country's unemployment rate. This implies that the high unemployment rate in Nigeria is not expected to revert to the equilibrium level without any drastic policy action. This finding of hysteresis in the unemployment rate is consistent with the studies by Furuoka, (2012), Dritsaki and Dritsaki (2013), Onwukeme and Opeloyeru (2015), Caporale and GilAlana (2018) and Pikoko and Phiri (2019).

Table 2: The Results of Linear Unit Root Tests

\begin{tabular}{|c|c|c|c|c|c|c|c|}
\hline \multirow[t]{2}{*}{$\begin{array}{l}\text { Unemployment } \\
\text { Rate }\end{array}$} & \multicolumn{2}{|c|}{ ADF } & \multicolumn{2}{|r|}{$\mathbf{P}-\mathbf{P}$} & \multicolumn{2}{|c|}{ KPSS } & \multirow[t]{2}{*}{$\begin{array}{c}\text { Order of } \\
\text { Integration }\end{array}$} \\
\hline & Level & 1st Diff. & Level & 1st Diff. & Level & 1st Diff. & \\
\hline With Constant & $\begin{array}{c}2.758 \\
(1.000) \\
\end{array}$ & $\begin{array}{c}-5.087^{* * *} \\
(0.000) \\
\end{array}$ & $\begin{array}{c}2.145 \\
(1.000) \\
\end{array}$ & $\begin{array}{c}-5.181^{* * *} \\
(0.000) \\
\end{array}$ & \begin{tabular}{|l}
$0.724^{* *}$ \\
$(0.463)$ \\
\end{tabular} & $\begin{array}{l}0.520^{* *} \\
(0.463) \\
\end{array}$ & $\mathrm{I}(1)$ \\
\hline $\begin{array}{l}\text { With Constant and } \\
\text { Trend }\end{array}$ & $\begin{array}{c}0.466 \\
(0.999)\end{array}$ & $\begin{array}{c}-4.243 * * * \\
(0.009)\end{array}$ & $\begin{array}{c}0.145 \\
(0.997)\end{array}$ & $\begin{array}{c}-5.999 * * * \\
(0.000)\end{array}$ & $\begin{array}{c}0.218 * * * \\
(0.216)\end{array}$ & $\begin{array}{c}0.077 \\
(0.119)\end{array}$ & $\mathrm{I}(1)$ \\
\hline $\begin{array}{l}\text { Without Constant and } \\
\text { Trend }\end{array}$ & $\begin{array}{c}3.280 \\
(1.000)\end{array}$ & $\begin{array}{c}-4.650 * * * \\
(0.000)\end{array}$ & $\begin{array}{c}3.261 \\
(1.000)\end{array}$ & $\begin{array}{c}-4.830 * * * \\
(0.000)\end{array}$ & - & - & $\mathrm{I}(1)$ \\
\hline
\end{tabular}




\section{Journal of International Cooperation and Development \\ www.richtmann.org/journal \\ Vol 3, No 1, May 2020}

Note1: The values in bracket denote the probability values which show the level of signficance of unemployment rate

Note 2: Null hypothesis for ADF and PP are unemployment rate has a unit root while the null hypothesis for KPSS is unemployment rate is stationary.

The next is to explain the results of the four nonlinear unit root tests as presented in Table 4. However, before explaining the results, it is expedient to test for the nonlinearity of the unemployment rate series. To do this, we used BDS independence test. The null hypothesis of the BDS is that economic series is linear. This is tested against the alternative hypothesis of nonlinearity. The results of the BDS test are reported in Table 3. From the results presented in the table, we reject the null hypothesis of linearity of unemployment rate series in favour of the alternative hypothesis of the nonlinearity of the series. This implies that the unemployment rate in Nigeria follows a nonlinear trend over time.

Now turning to the explanation of the results from the nonlinear unit root test methods. It is observed that the results are mixed. While the KSS, Kruse and FADF results support the UHH, QADF results, on the other hand, support the natural rate of unemployment hypothesis. Judging by majority rule, it can be submitted that UHH holds in Nigeria even when we used nonlinear unit root test estimation techniques. Hence, the present level of unemployment is likely to be sustained in the future except a policy action is taken to address the current increase in unemployment figure. However, the results from the quantile unit root test method showed that unemployment can revert to its long-run equilibrium provided that the policy actions are taken as quickly as possible. Therefore, frequent policy action, especially every quarter, is required to control the unemployment problem in Nigeria.

Table 3: BDS test for linearity

\begin{tabular}{|c|c|c|}
\hline Dimension & BDS Statistic & Prob. \\
\hline 2 & 0.146 & 0.000 \\
\hline 3 & 0.228 & 0.000 \\
\hline 4 & 0.266 & 0.000 \\
\hline 5 & 0.277 & 0.000 \\
\hline 6 & 0.264 & 0.000 \\
\hline
\end{tabular}

Source: Authors' computation 


\section{Journal of International Cooperation and Development}

www.richtmann.org/journal

Vol 3, No 1, May 2020

Table 4: The Results of Nonlinear Unit Root Tests

\begin{tabular}{|c|c|c|c|c|c|c|c|c|}
\hline \multicolumn{2}{|c|}{ KSS } & \multicolumn{2}{|c|}{ KRUISE } & \multicolumn{2}{|c|}{ FADF } & \multicolumn{3}{|c|}{ QADF } \\
\hline Variable & Coefficient & Variable & Coefficient & Variable & Coefficient & Quantile & Variable & Coefficient \\
\hline unemp $(-1)^{\wedge} 3$ & $\begin{array}{c}1.49 \mathrm{E}-07 \\
(0.383)\end{array}$ & (unemp $(-1))^{\wedge} 3$ & $\begin{array}{c}-6.94 \mathrm{E}-05 \\
(0.552)\end{array}$ & $\sin 2 \pi k t / T$ & $\begin{array}{c}0.075 \\
(0.772) \\
\end{array}$ & 10 & unemp & $\begin{array}{c}1.061 \\
(0.000)\end{array}$ \\
\hline $\mathrm{D}($ unemp $(-1))$ & $\begin{array}{c}3.693 \\
(0.000) \\
\end{array}$ & (unemp $(-1))^{\wedge} 2$ & $\begin{array}{c}0.006 \\
(0.001)\end{array}$ & $\cos 2 \pi \mathrm{kt} / \mathrm{T}$ & $\begin{array}{c}-0.108 \\
(0.712)\end{array}$ & 20 & Unemp & $\begin{array}{c}1.064 \\
(0.000)\end{array}$ \\
\hline $\mathrm{D}($ unemp $(-2))$ & $\begin{array}{c}-5.413 \\
(0.000) \\
\end{array}$ & & & uemp(-1) & $\begin{array}{c}0.167 \\
(0.027)\end{array}$ & 30 & Unemp & $\begin{array}{c}1.067 \\
(0.000)\end{array}$ \\
\hline$D($ unemp $(-3))$ & $\begin{array}{c}4.142 \\
(0.000)\end{array}$ & & & uemp(-2) & $\begin{array}{l}-0.079 \\
(0.474)\end{array}$ & 40 & Unemp & $\begin{array}{c}1.070 \\
(0.000)\end{array}$ \\
\hline $\mathrm{D}($ unemp $(-4))$ & $\begin{array}{c}-2.047 \\
(0.069) \\
\end{array}$ & & & uemp(-3) & $\begin{array}{c}0.040 \\
(0.710) \\
\end{array}$ & 50 & Unemp & $\begin{array}{c}1.076 \\
(0.000) \\
\end{array}$ \\
\hline $\mathrm{D}($ unemp $(-5))$ & $\begin{array}{c}0.862 \\
(0.210)\end{array}$ & & & uemp(-4) & $\begin{array}{c}-0.163 \\
(0.031)\end{array}$ & 60 & Unemp & $\begin{array}{c}1.080 \\
(0.000)\end{array}$ \\
\hline $\mathrm{D}($ unemp $(-6))$ & $\begin{array}{c}-0.240 \\
(0.211) \\
\end{array}$ & & & & & 70 & Unemp & $\begin{array}{c}1.075 \\
(0.000) \\
\end{array}$ \\
\hline & & & & & & 80 & Unemp & $\begin{array}{c}1.073 \\
(0.000)\end{array}$ \\
\hline & & & & & & 90 & Unemp & $\begin{array}{c}1.069 \\
(0.000)\end{array}$ \\
\hline
\end{tabular}

Note 1; Null hypothesis for QADF, KSS and FADF are un has a unit root while the null hypothesis for Kruse is un is stationary. Note $2 ; * * * * *$ and $*$ represent $1 \%, 5 \%$ and $10 \%$ respectively. Note 3: PV and LS denote probability value and level of significance respectively.

\section{Conclusion and Policy Recommendations}

The study re-examines the validity of $\mathrm{UHH}$ in Nigeria using the data of the unemployment rate from 1970-2017. The goal of this study is to confirm whether UHH is valid when nonlinearity that usually characterises some macroeconomic series is taking into consideration. Consequently, apart from using linear unit root tests techniques such as ADF, P-P and KPSS, we also employed four nonlinear unit root tests such as KSS, Kruse, FADF and QADF unit root tests. The results from linear unit root tests affirm or confirm UHH. This implies that shocks that cause unemployment problem would have a permanent effect on unemployment in Nigeria. However, the findings from the nonlinear unit root tests are mixed. The KSS, Kruse and FADF unit root tests results show that the unemployment rate in Nigeria follows the hysteresis process while QADF unit root test results show that unemployment rate follows a natural rate of unemployment. This implies that a shock to the economy such as oil price shock can aggravate the unemployment problem in Nigeria.

Given the results, solving the unemployment problem in Nigeria will require holistic policy actions. The demand-side management governed by the use of fiscal policy instruments may not suffice to combat unemployment problem in Nigeria. There is a need to combine fiscal policy with other conventional and unconventional policies to address the unemployment problem in the country. 


\section{Journal of International Cooperation and Development}

www.richtmann.org/journal

Vol 3, No 1, May 2020

\section{References}

Aminu, A., \& Raifu, I. A. (2018). A reconsideration of Okun's law: An application of symmetric and asymmetric approaches on Nigerian data. West African Financial and Economic Review, 18(1), 77-106.

Ayinde, O. T., \& Egbetunde, T. (2015). Population growth, hysteresis and development outcomes in Sub-Saharan African economies-A case of Nigeria. Journal of Mauritius Research Journal, Vol. 21, pp. 525-552

Ayinde, O. T., Egbetunde, T., \& Bankole, A. S. (2014). Unemployment hysteresis in Nigeria: Any role for monetary policy?. Nigerian Journal of Economics and Social Sciences (NJESS), Vol. 56, No. 3, pp. 347-408

Bahmani-Oskooee, M., Chang, T., \& Ranjbar, O. (2018), Testing hysteresis effect in US states unemployment: new evidence using a nonlinear quantile unit root test. Applied Economics Letters, 25(4), 249-253.

Barro, R. J (1988). The Persistent of Unemployment. The American Economic Review, 78(2), 32-37

Blanchard, O. J. \& Summers, L. H. (1986a). Hysteresis in unemployment problem. NBER Working Paper no. 2035.

Blanchard, O. J. \& Summers, L. H. (1986b). Hysteresis and the European unemployment problem. NBER Working Paper no. 1950.

Bolat, S., Tiwari, A. K., \& Erdayi, A. U (2014). Unemployment hysteresis in the Eurozone area: evidences from nonlinear heterogeneous panel unit root test. Applied Economics Letters, 21(8), 536-540.

Caporale, G. M., \& Gil-Alana, L. A. (2018). The asymmetric behaviour of Spanish unemployment persistence. Economics Bulletin, 38(1), 98-104.

Caporale, G. M., \& Gil-Alana, L. A. (2018). Unemployment in Africa: a fractional integration approach. South African Journal of Economics, 86(1), 76-81.

Chang, T. (2011). Hysteresis in unemployment for 17 OECD countries: Stationary test with a Fourier function. Economic Modelling, 28(5), 2208-2214.

Chang, T., Yang, M. J., Liao, H. C., \& Lee, C. H. (2007). Hysteresis in unemployment: empirical evidence from Taiwan's region data based on panel unit root tests. Applied Economics, 39(10), 1335-1340.

Choudhry, M., Marelli, E., \& Signorelli, M. (2012.Youth unemployment rate and impact of financial crises. International journal of manpower, 33(1), 76-95.

Dickey, D. A., \& Fuller, W. A. (1979). Distributions of the estimators for autoregressive time series with a unit root. Journal of American Statistical Association, 74, pp. 427-431

Dritsaki, C., \& Dritsaki, M. (2013). Hysteresis in unemployment: An empirical research for three member states of the European Union. Theoretical \& Applied Economics, 20(4).

Eisazadeh, S., \& Tabarsi, M. (2013). Does Unemployment Hysteresis Exist in Economy of Iran? International Journal of Asian Social Science, 3(8), 1717-1724.

Enders, W., \& Lee, J. (2004). Testing for a unit root with a nonlinear Fourier function. In Econometric Society 2004 Far Eastern Meetings (Vol. 457).

Enders, W., \& Lee, J. (2012). A unit root test using a Fourier series to approximate smooth breaks. Oxford Bulletin of Economics and Statistics, 74(4), 574-599. 


\section{Journal of International Cooperation and Development}

www.richtmann.org/journal

Vol 3, No 1, May 2020

Folawewo, A. O., (2012). Is there hysteresis in Nigerian unemployment rate? An application of the unit root test with structural breaks. The Nigerian Journal of Economics and Social Studies, Vol. 54, No.3, pp. 313-328.

Friedman, M. (1968). The role of monetary policy. American Economic Review 58: 1-17.

Furuoka, F. (2012). Unemployment hysteresis in the East Asia-Pacific region: new evidence from MADF and SURADF tests. Asian-Pacific Economic Literature, 26(2), 133-143.

Furuoka, F. (2014a). Are unemployment rates stationary in Asia-Pacific countries? New findings from Fourier ADF test. Economic research-Ekonomska istraživanja, 27(1), 34-45.

Furuoka, F. (2014b). Does hysteresis exist in unemployment? New findings from fourteen regions of the Czech Republic. Finance a Uver: Czech Journal of Economics \& Finance, 64(1).

Furuoka, F. (2014c). Hysteresis effect on unemployment: evidence from the Visegrad Countries. Ekonomický časopis, 62(02), 185-198.

Galí, J. (2015). Hysteresis and the European unemployment problem revisited. (No. w21430). National Bureau of Economic Research.

Gözgör, G. (2013). Unemployment persistence and inflation convergence: Evidence from regions of Turkey. Regional and Sectoral Economic Studies, 13(1), 55-64.

Gustavsson, M and Österholm, P. (2007). Does unemployment hysteresis equal employment hysteresis? Economic Record, 83(261), 159-173.

Hayashi, F. (2000). Econometrics. Princeton University Press

Kapetanios, G., Shin, Y., \& Snell, A. (2003). Testing for a unit root in the nonlinear STAR framework. Journal of econometrics, 112(2), 359-379.

Khraief, N., Shahbaz, M., Heshmati, A., \& Azam, M. (2018). Are unemployment rates in OECD countries stationary? Evidence from univariate and panel unit root tests. The North American Journal of Economics and Finance, 100838.

Koenker, R., \& Xiao, Z. (2004). Unit root quantile autoregression inference. Journal of the American Statistical Association, 99(467), 775-787.

Kruse, R. (2011). A new unit root test against ESTAR based on a class of modified statistics. Statistical Papers, 52(1), 71-85.

Kula, F. and Aslan, A. (2010). Hysteresis vs. natural rate of unemployment: One, the other, or both? South-East European Journal of Economics and Business, 5(1), 91-94

Kwiatkowski, D., Phillips, P. Schmidt, P., \& Shin, Y. (1992). Testing the null hypothesis of stationarity against the alternative of a unit root. Journal of Econometrics, 54, pp. 159-178

Lee, H. Y., Wu, J. L., \& Lin, C. H. (2010). Hysteresis in East Asian unemployment. Applied Economics, 42(7), 887-898.

Lin, C. H., Kuo, N. F., and Yuan, C. D. (2008). Nonlinear vs. nonstationary of hysteresis in unemployment: evidence from OECD economies. Applied Economics Letters, 15(6), 483-487.

Neftci, S. N. (1984). Are economic time series asymmetric over the business cycle?. Journal of Political Economy, 92:307-328

Nelson, C. R., \& Plosser, C. R. (1982). Trends and random walks in macroeconomic time series: some evidence and implications. Journal of monetary economics, 10(2), 139- 162.

Nuga, B. O., \& Asimiea, A. O. (2015). SWOT analysis of the Nigerian agricultural sector. IOSR Journal of Agriculture and Veterinary Science Ver. II, 8(4), 2319-2372.

Ofuoku, A.U., \& Chukwuji, C.O. (2012). The impact of rural-urban migration on plantation agriculture in the Niger Delta region, Nigeria. Journal of Rural Social Sciences, 27(1):13-151 


\section{Journal of International Cooperation and Development}

www.richtmann.org/journal

Vol 3, No 1, May 2020

Olanipekun, I.O., S. Saint Akadiri, O. Olawumi and F.V. Bekun 2017. Does the labour market hysteresis hold in low-income countries? International Journal of Economics and Financial Issues, 7(1), 19-23.

Onwukeme, O., \& Opeloyeru, O. (2015). Does unemployment hysteresis Exist in Nigeria?. The West African Social and Management Sciences Review, Vol. 6, No. 2. pp 24-42.

Phelps, E. (1967). Phillips curves, expectations of inflation and optimal unemployment over time. Economica 34: 254-281.

Phelps, E. (1972). Inflation policy and unemployment theory: The cost-benefit approach to monetary Planning. Macmillan.

Phelps, E. S. (1994). Structural slumps: The modern equilibrium theory of unemployment, interest, and assets. Harvard University Press.

Phillips, P.C., \& Perron, P. (1988). Testing for a unit root in time series regression. Biometrika, 75, pp. 335-346

Pikoko, V., \& Phiri, A. (2019), Is there hysteresis in South African unemployment? Evidence from the post-recessionary period, Acta Universitatis Danubius. CEconomica, 15(3).

Raifu, I. A. (2017). On the determinants of unemployment in Nigeria: What are the roles of trade openness and current account balance?. Review of Innovation and Competitiveness: $A$ Journal of Economic and Social Research, 3(4), pp. 5-30.

Raifu, I. A. (2019). The effect of financial development on unemployment in Nigeria: Do measures of financial development matter?. DBN Journal of Economics and Sustainable Growth Vol. 2, Issue 2, pp. 1-35.

Romer, C. (2012). Fiscal policy in the crisis: Lessons and policy implications. IMF Fiscal Forum, Vol. 18

Romero-Avila, D., \& Usabiaga, C. (2007). Unit root tests, persistence, and the unemployment rate of the US states. Southern Economic Journal, 698-716.

Valera, H. G. A., Holmes, M. J., \& Hassan, G. M. (2017). How credible is inflation targeting in Asia? A quantile unit root perspective. Economic Modelling, 60, 194-210

Xie, H., Chang, T., Grigorescu, A., \& Hung, K. (2018). Revisit Hysteresis Unemployment in Eastern European Countries using Quantile Regression. Ekonomický časopis, 66(5), 522-537.

Yaya, O. S., Ogbonna, A. E., \& Mudida, R. (2019). Hysteresis of unemployment rates in Africa: new findings from Fourier ADF test. Quality \& Quantity, 53(6), 2781-2795.

Yilanci, V. (2008). Are unemployment rates nonstationary or nonlinear? Evidence from 19 OECD countries. Economics Bulletin, 3(47), 1-5.

Yushi, J., \& Tsangyao, C. (2016). Bring Quantile unit root test back in testing hysteresis in unemployment for the United States. Romanian Journal of Economic Forecasting, 19(1). 513 